\title{
Centro Nacional Arte Contemporáneo Cerrillos (CNACC): motor de transformación de la ciudad de Santiago
}

\author{
Centro Nacional Arte Contemporáneo Cerrillos (CNACC): A transformation tool for Santiago de Chile
}

\section{Laura Gallardo Frías*, María Isabel Toledo Jofré**, Consuelo Figueroa Garavagno**, Javier Vera Bravo**, Luis Pérez Huenupi**}

Recibido: 01 de febrero de 2019

Aceptado: 19 de junio de 2019

\section{Resumen}

Los centros de arte contemporáneo son considerados piezas motoras de transformación urbana, lo que se ha constatado en numerosas ciudades de todo el mundo. El objetivo de este artículo es analizar el Centro Nacional de Arte Contemporáneo Cerrillos (CNACC), como motor de transformación de la ciudad. Se trata de una investigación cualitativa y descriptiva que analiza un caso único de tipo institucional. Para la recolección de información se despliega una estrategia multimétodo: análisis de documentación histórica, análisis planimétrico urbano y arquitectónico y estudio etnográfico. Como resultado se presentan los aspectos centrales de la historia del edificio y del sector, la relación del Centro con la ciudad, se caracteriza la edificación y se reporta la experiencia de los habitantes. Luego se establece la capacidad del CNACC para operar como motor de transformación a partir de cinco elementos: conectividad, legibilidad, accesibilidad, recorridos y permanencias, y flexibilidad. Se concluye que el Centro Nacional de Arte Contemporáneo Cerrillos cuenta con las condiciones estructurales o de base que le otorgan el potencial necesario para llegar a constituirse en un motor de transformación de la ciudad.

Palabras clave: Centro de arte contemporáneo, área Metropolitana, movilidad sostenible, participación ciudadana, urbanismo y arquitectura, visitante.

\begin{abstract}
Contemporary art centers are considered motor parts of urban transformation, which has been observed in many cities around the world. The objective of this article is to analyze the Centro Nacional de Arte Contemporáneo Cerrillos, -Cerrillos National Center of Contemporary Art-, (CNACC), as the engine of transformation of the city. It is a qualitative and descriptive research that analyzes a unique case of institutional type. For the collection of information, a multi-method strategy is deployed: analysis of historical documentation, urban and architectural planimetric analysis and ethnographic study. As a result, the central aspects of the history of the building and the sector, the relationship between the CNACC and the city are presented, the building is characterized, and the experience of the inhabitants is reported. Then the CNACC's capacity to operate as a transformation engine is established based on five elements: connectivity, readability, accessibility, paths and permanence, and flexibility. It is concluded that the Cerrillos National Center of Contemporary Art has the structural or basic conditions that give it the necessary potential to become an engine of transformation of the city.
\end{abstract}

Keywords: architecture, contemporary art center, urbanism, visitor.

\footnotetext{
* Filiación: Universidad de Chile, Santiago, Chile. Contacto: lauragallardofrias@uchilefau.cl, luisperezhuenupi@gmail.com

** Filiación: Universidad Diego Portales, Santiago, Chile. Contacto: maria.toledo@udp.cl, consuelo.figueroa@udp.cl, javerab@gmail.com
}

Este artículo forma parte del proyecto de investigación FONDECYT № 11170140 financiado por el Fondo Nacional de Desarrollo Científico y Tecnológico de Chile y el Programa de Apoyo a la Productividad Académica, PROA VID 2018, Universidad de Chile. 
Cómo citar: Gallardo Frías, L., Toledo Jofré, M. I., Figueroa Garavagno, C., Vera Bravo, J. y Pérez Huenupi, L. (2019). Centro Nacional Arte Contemporáneo Cerrillos (CNACC): motor de transformación de la ciudad de Santiago. Revista de Urbanismo, 40, 1-18. https://doi.org/10.5354/0717-5051.2018.52362 


\section{Introducción}

Los museos y centros de arte contemporáneo han funcionado como motor de transformación en numerosas ciudades del mundo, siendo capaces de rehabilitar y reestructurar áreas urbanas. La etimología de "motor" viene del latín, s. XVII, motor, motoris "que mueve, movedor" (Corominas, 1987, p. 405), es decir, lo que impulsa o imprime movimiento. Aristóteles habla del "primer motor inmóvil" para referirse al principio que mueve todas las cosas, esencia y actualidad pura, al que llama dios (Echegoyen, 1996). Numerosos autores, como Layuno (2003) o Galland (2014), entre otros, se han referido al concepto de "motor de transformación" al plantear los centros de arte y centros culturales como impulsores del desarrollo no solamente de un barrio o sector específico, sino de la ciudad.

Existen numerosos ejemplos internacionales sobre cómo estos centros han impulsado sectores de la ciudad, en los cuales el vínculo con sus habitantes ha sido un factor clave para la regeneración de barrios. El Centro Georges Pompidou de París (1977) de los arquitectos Renzo Piano y Richard Rogers, constituye un motor de regeneración cultural que anula las fronteras entre arte y vida cotidiana (Zunzunegui, 1990). A partir de este hito, los museos y centros de arte se conciben como una continuidad entre interior y exterior, y el espacio museístico se expande hacia una plaza abierta a numerosas actividades, conectándose con su comunidad (Layuno, 2003). En la misma línea, es decir, con el fin de atraer la atención de sus ciudadanos, generar un hito urbano e incentivar la actividad económica y política, surge el Guggenheim de Bilbao (1997), obra de Frank Gehry. Su impacto es de tal magnitud que el Efecto Guggenheim (Esteban, 2007) se replica en otras ciudades para regenerar sectores industriales como el caso de la Fundación Dia Center for the Arts en Nueva York y la reapertura del Museo de Antioquia de Medellín, Colombia.

En el plano nacional, la reciente investigación titulada Los museos de arte como mecanismos de inclusión y exclusión social en el arte y en la sociedad: un estudio de caso en Chile, concluye que "los museos de arte pueden operar como mecanismos de inclusión social en el sistema funcional de arte y en la sociedad..." (Valenzuela, Espinosa, Madero-Cabib, Moyano y Ortiz, 2015, p. 734), lo que confirma el rol que puede tener la constitución de un centro de arte contemporáneo en áreas desvalorizadas de la ciudad. Sin embargo, en Chile no se han realizado investigaciones que se enfoquen específicamente en este tema, ya que la mayoría de ellas se han realizado

bajo el enfoque de 'consumo cultural'. Esta perspectiva reduce la mirada sobre el acercamiento al arte visual que también se puede analizar desde otros enfoques. Por ejemplo, aquellas que consideran que una obra de arte involucra diversas formas de 'sentir-pensar-saber' que no necesariamente son inmediatas. (Consejo Nacional de la Cultura y las Artes, s.f., p. 27).

Por ello, sería relevante que las investigaciones consideren la relación entre visitantes, centros y arte (Consejo Nacional de la Cultura y las Artes, s.f.).

El objetivo de este artículo es analizar un centro de arte contemporáneo en tanto motor de transformación de la ciudad. Por ello, se estudia el Centro Nacional de Arte Contemporáneo Cerrillos (CNACC), único en su tipo, que, además, se ubica fuera de la zona de concentración de instituciones culturales de Santiago.

\section{Metodología}

Esta es una investigación de tipo cualitativa y descriptiva. Se trata de un estudio de caso singular, es decir, un corpus empírico que se representa en singular, específicamente, un caso institucional. Se estudia en profundidad porque permite aprender de su análisis y puede contribuir de manera significativa a la producción de conocimiento, siendo a la vez una vía de acceso a otros fenómenos o aspectos del caso (Pires, 1997).

Como metodología se despliega una estrategia multimétodo que contempla el análisis de documentación histórica y material bibliográfico un estudio planimétrico a escala de ciudad, comuna y barrio con superposición de capas de información, un estudio planimétrico arquitectónico estructurado en una secuencia desde el exterior hacia el interior, y un estudio de tipo etnográfico con observación participante y relatos solicitados. La información recolectada se presenta en un texto conformado por cuatro partes que refieren a los principales acontecimientos ocurridos en el sector y en la edificación; a la relación del CNACC con la ciudad, la comuna y el barrio; al funcionamiento del centro de arte; 
y a la caracterización de sus visitantes y su experiencia de visita.

Para el análisis de datos se utiliza la técnica de análisis de contenido en su versión inductiva (Mayring, 2014), es decir, a partir de la lectura del material recolectado se identifican los elementos de análisis del CNACC como motor de transformación de la ciudad.

\section{Análisis del centro Nacional De Arte Contemporáneo Cerrillos (CNACC)}

\section{Historia del CNACC}

Hasta inicios del siglo pasado, en la zona donde actualmente se emplaza el CNACC se ubicó el Fundo Los Cerrillos, destinado a la producción agropecuaria. Fue a partir de los años 30, cuando se inició el vertiginoso crecimiento urbano de Santiago (De Ramón, 2000), que el sector comenzó a ser incorporado a la ciudad. El hito más relevante de la época en la zona fue la apertura del primer aeropuerto de Chile. Emblema de progreso y modernidad, se transformó en el centro neurálgico que, durante las siguientes décadas, unió por aire al territorio nacional, estableciendo una creciente comunicación con el exterior.

Las obras del primer aeropuerto de Chile, a cargo de los arquitectos del Ministerio de Obras Públicas: Jorge Ugarte, Eduardo Arrau y Juan Mena, comenzaron en 1929. Esta obra fue parte del plan modernizador del Estado, impulsado por el gobierno de Ibáñez del Campo, que creó numerosas instituciones, entre ellas, la Fuerza Aérea de Chile (1928) y la Línea Aérea Nacional (1929). El dinero para la construcción del aeropuerto fue donado por Daniel Guggenheim, miembro de una de las familias más ricas de EE. UU. que, desde principios de siglo, mantenía capitales en la minería en Chile y otras partes del mundo. Esta inyección financiera se enmarcó en la creciente llegada de capitales norteamericanos en forma de créditos, inversiones y donaciones que desplazaron a las inversiones europeas (Rinke, 2013).

Sin embargo, en 1931, los efectos de la Gran Depresión, la paralización de los distintos sectores de la economía, la caída del gobierno de lbáñez y la fuerte agitación revolucionaria, obligó a la paralización de las obras. Estas solo fueron retomadas en el año 1933, bajo el segundo gobierno de Alessandri Palma quien impulsó un amplio plan de obras públicas tendiente a revertir los graves niveles de cesantía en el país (Correa, et.al., 2001). El edificio fue finalmente inaugurado en 1934.

En 1930, se instaló en Cerrillos la Curtiss Wright Export Co., la primera y única fábrica de aviones del país, controlada desde 1936 por la Línea Aérea Nacional. En 1945, se pavimentó una pista de aterrizaje de 2.000 metros de longitud por 45 metros de ancho, además de calles de rodaje y una plataforma frente al edificio terminal. Ese mismo año se construyó la primera torre de control del país, hasta hoy, reconocida como ícono del aeropuerto (Figuras 1 y 2). De ese tiempo data también la instalación de las primeras radio-ayudas, luces de pistas y reforzamiento de equipos de salvamento y extinción de incendios. En 1957 se efectuó una remodelación del edificio terminal, siguiendo el diseño propuesto por la arquitecta Iris Valenzuela, del Ministerio de Obras Públicas, que, a partir de la incorporación del Mural de los Cóndores, obra de Samuel Román Rojas y su hijo Héctor Román Latorre, eliminó las curvas de la fachada norte. Este último -Héctor Román- también fue el autor del mural que se ubica en el interior del edificio. Ambos murales persisten hasta hoy. Además, se amplió la pista de aterrizaje que llegaría a 2.342 metros de largo (Eliash, 2013, p. 5). Sin embargo, el crecimiento urbano de Santiago imposibilitó la extensión de su pista de aterrizaje. 


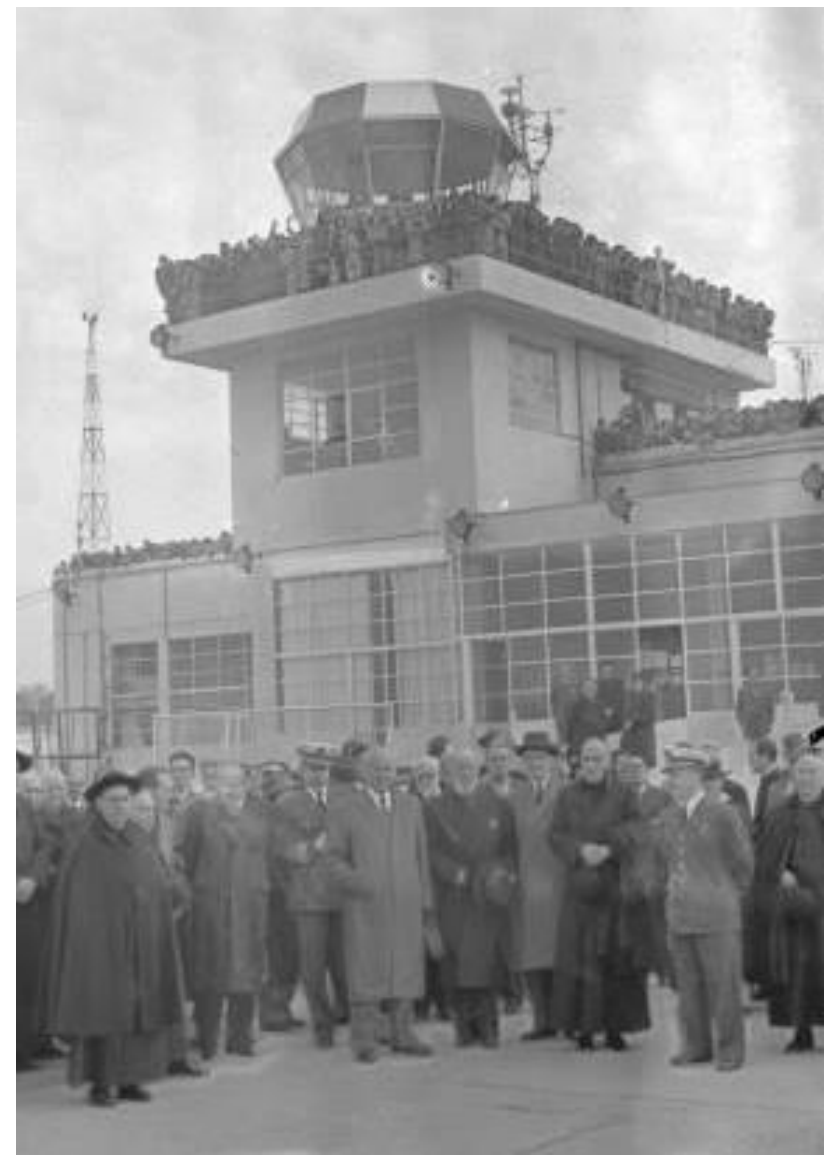

Figura 1. Recibimiento Cardenal José María Caro, 1946. Fuente: Colección Museo Histórico Nacional. Autor: Miguel Rubio Feliz.

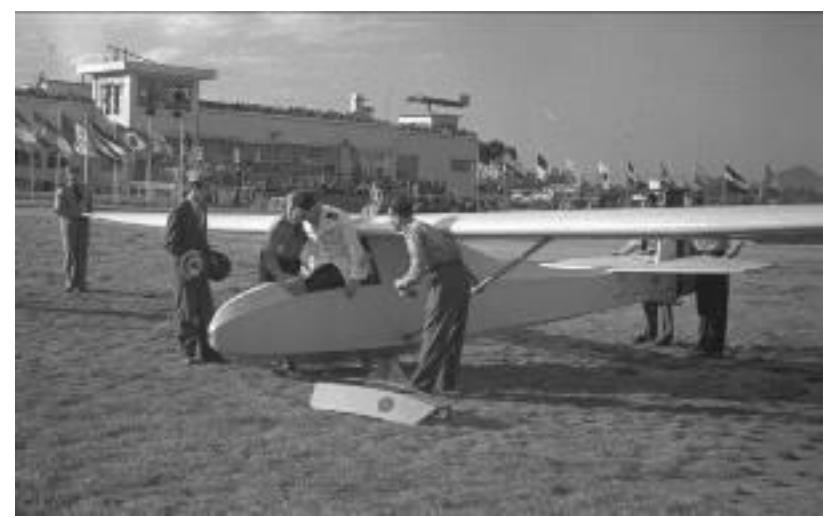

Figura. 2. Recibimiento Cardenal José María Caro. Fuente: Colección Museo Histórico Nacional. Autor: Miguel Rubio Feliz.

Es por esta razón que, en 1961, durante el segundo gobierno de Carlos Ibáñez del Campo, empezó a construirse el Aeropuerto de Pudahuel, inaugurado en febrero de 1967. Desde esa fecha hasta el 2006 Cerrillos siguió funcionando como aeródromo para viajes de cabotaje interno, algunos vuelos de la FACH y de las escuelas de aviación. Paulatinamente fue ocupando un lugar secundario en las comunicaciones aéreas nacionales. Las líneas aéreas LAN Chile y LADECO dejaron de utilizar este recinto en 1975 y 1981 respectivamente (Eliash, 2013, p. 5). Pese a que desde 1992 hasta su cierre tuvo lugar allí la Feria Internacional del Aire y del Espacio (FIDAE), esta no logró revitalizar el aeródromo. En 2006 la FACH trasladó su base aérea a El Bosque y traspasó los terrenos del aeropuerto al Servicio de Vivienda y Urbanismo (SERVIU) Metropolitano, lo que llevó al cierre definitivo del terminal aéreo. En 2016, la presidenta Bachelet anunció la creación del Centro de Arte Contemporáneo Cerrillos, que fue inaugurado en septiembre de ese mismo año.

La zona en que se encuentra ubicado el CNACC, también sufrió cambios durante el siglo pasado. Junto a la apertura del aeropuerto de Cerrillos, el sector, predominantemente agrícola en sus inicios, comenzó un creciente auge industrial a partir del proceso de industrialización sustitutiva de importaciones, impulsado, desde la década de 1940, por la Corporación de Fomento de la Producción (CORFO), la que dio facilidades tributarias para la apertura de plantas industriales. Además, se crearon vías camineras y férreas. Hacia fines de 1950, la construcción de un oleoducto cuyo terminal se ubicó en el Camino a Melipilla, aceleró este proceso (Montalbán, 1996). La instalación de fábricas en la zona atrajo también a población trabajadora que se asentó en los nuevos barrios obreros, coexistiendo con la población rural que allí habitaba. Durante los años sesenta y, particularmente, en los inicios de los setentas, el sector alcanzó gran protagonismo en la escena política, por los altos niveles de sindicalización y la creación, en 1972, del primer Cordón Industrial Cerrillos-Maipú, que exigía el traspaso de las fábricas al control del Estado (Mujica, s.f., p.9).

El golpe militar de 1973 puso fin a este movimiento. Según reporta el Informe de la Comisión Nacional sobre Prisión Política y Tortura, en Cerrillos operaron como centros de detención el recinto FISA, el retén de carabineros, la Subcomisaría Vista Alegre y uno de los hangares del aeródromo de Cerrillos (Comisión Nacional sobre Prisión Política y Tortura, 2005, p. 455).

Hasta ese momento, gran parte del sector de lo que hoy es Cerrillos aún estaba comprendido dentro de la Comuna de Maipú, y un pequeño retazo, en la Comuna de Santiago. En 1981, la dictadura liderada por Augusto 
Pinochet creó 17 comunas nuevas, siguiendo lógicas políticas "despolitizadoras" con el fin de fortalecer la centralización a partir de la fragmentación de los espacios nacionales, regionales y comunales (Valdivia, 2015), de modo de controlar la subversión y delimitar los focos de pobreza. Una de ellas fue Cerrillos. No obstante, la vigencia de este Decreto con Fuerza de Ley, la comuna no se instaló como tal sino hasta el año 1991, momento en que fue designado el primer alcalde comunal.

En 2008 el Ministerio de Vivienda y Urbanismo abrió un concurso para el diseño y construcción de la Ciudad Parque Bicentenario en los terrenos del aeródromo Cerrillos. El objetivo del Plan Maestro era propender "a la generación de condiciones urbanas apropiadas para la consolidación del proceso de reconversión de los vacíos interiores urbanos [...] desde la perspectiva de un desarrollo urbano integrador, integral y amable con su medio ambiente" (Galilea, 2006, p.58). El equipo liderado por el arquitecto Humberto Eliash se adjudicó el diseño.

La apertura del Centro de Arte Contemporáneo Cerrillos en 2016 significó, en palabras del entonces Ministro de Cultura Ernesto Ottone:

la recuperación de un espacio para un proyecto inédito, impulsado plenamente por el Estado y desde el cual se desarrollará de manera integral el trabajo en torno a las políticas públicas, investigación, experimentación y al mismo tiempo exhibición y mediación del arte contemporáneo, en una comuna que se levanta como futuro polo cultural para Santiago y todo el país. (Ministerio de las Culturas, las Artes y el Patrimonio, 2016, p. 6)

Según se explicita en el catálogo de la exposición con que se inauguró el centro, titulado Una imagen llamada palabra, este tiene por misión “... promover y estimular la creación, experimentación, reflexión y comprensión del arte contemporáneo chileno, en conexión con la escena latinoamericana, poniendo a disposición de la ciudadanía las herramientas para su conservación, investigación, educación y difusión" (CNACC, 2016, p.8).

\section{Relación del CNCAA con la ciudad}

En Santiago de Chile las obras arquitectónicas destinadas al arte -museos, centros culturales y galerías- se encuentran concentradas en el sector centro-oriente de la ciudad, dejando al resto de las comunas desprovistas de lugares para el arte, como se puede observar en el plano de emplazamiento del CNACC ( Figura 3 ). En este sentido, la apertura del centro en la Comuna de Cerrillos, al Sur Poniente de Santiago, constituye una excepción.

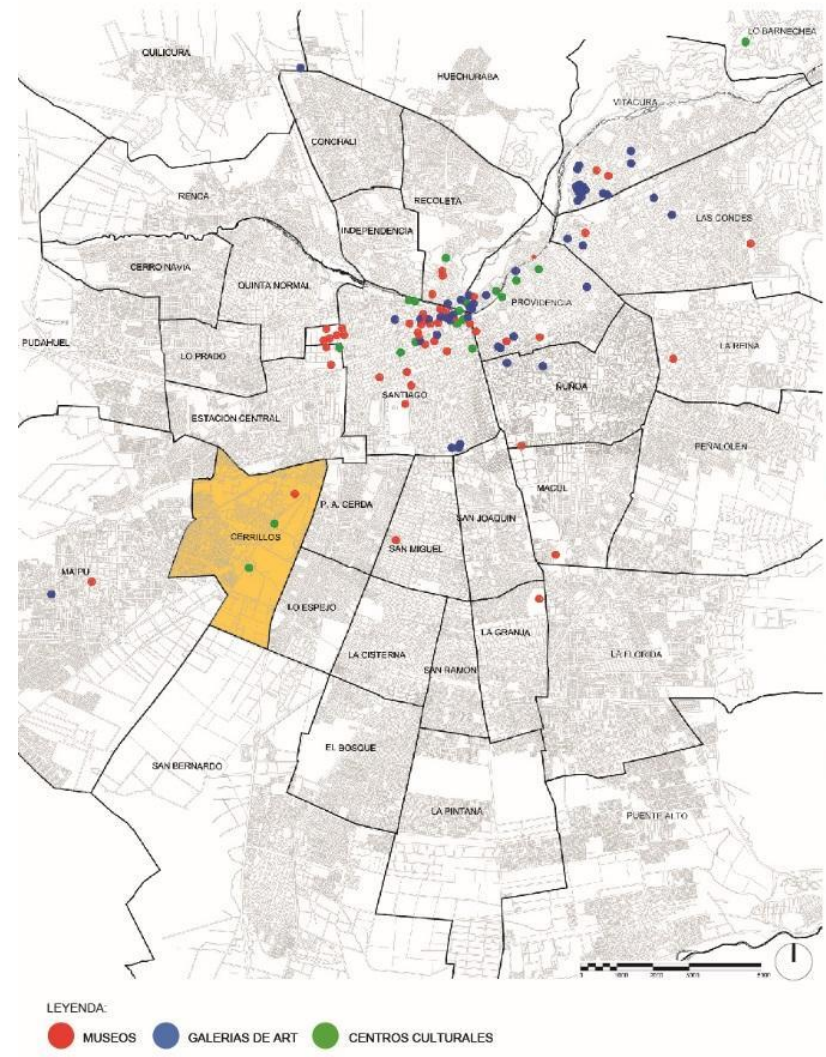

Figura 3. Emplazamiento del CNACC. Plano de emplazamiento del CNACC en relación a la ciudad y las distintas obras arquitectónicas destinadas al arte.

Fuentes: Elaboración propia en base a Plano Comunal de Santiago recopilado de www.sitio.cartografia.cl

Una de las principales características de esta comuna es la existencia de gran cantidad de viviendas sociales en un sector industrial. Según la llustre Municipalidad "Cerrillos es una comuna residencial, industrial y comercial que se proyecta y consolidará como un Subcentro Metropolitano de servicios, a escala humana, sustentable y moderno" (Ilustre Municipalidad de Cerrillos, 2011, p. 88).

Las vías principales de conexión del CNACC con la ciudad son, como se muestra en el plano (Figura 4): Av. Pedro Aguirre Cerda, Américo Vespucio, Av. Lo Errázuriz y Av. Departamental, las que permiten conectar también los principales hitos urbanos de la comuna. 


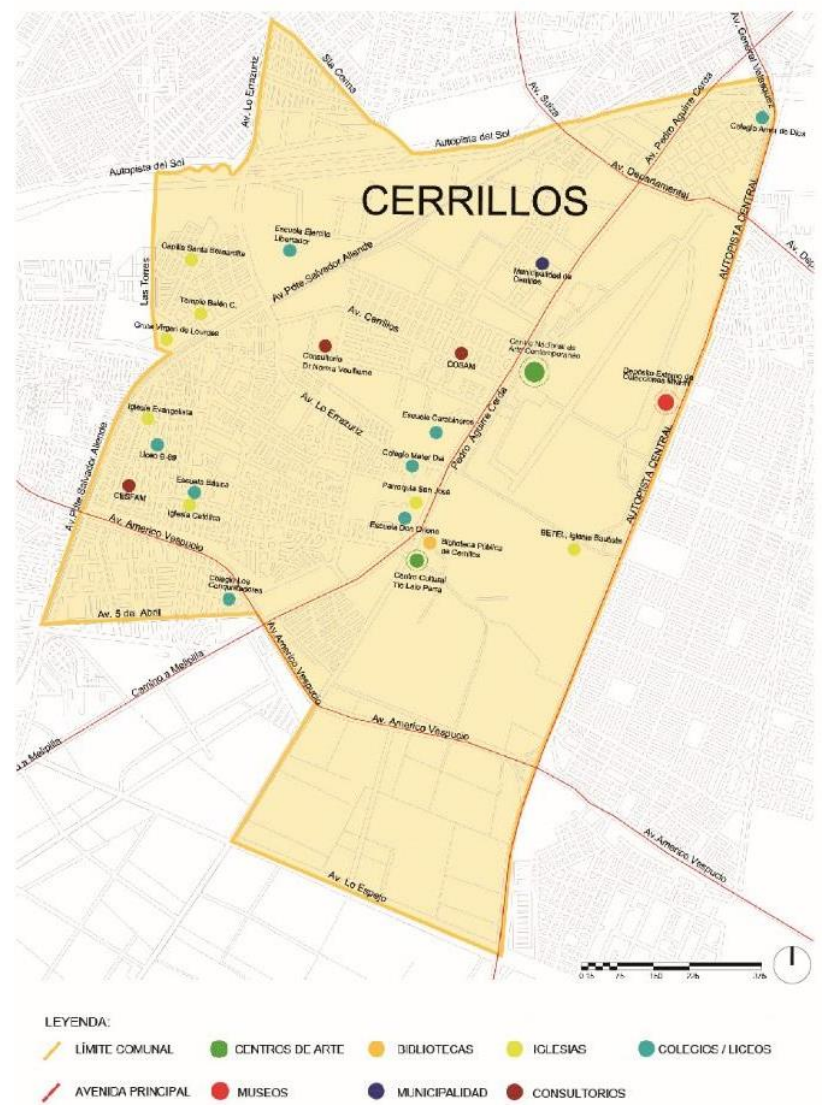

Figura 4. Plano de emplazamiento del CNACC en la comuna de Cerrillos. Relación con vías principales de conexión y edificaciones públicas representativas. Fuente: Elaboración propia en base a Plano Comunal de Santiago recopilado de www.sitio.cartografia.cl

Alrededor del CNACC existen numerosos terrenos baldíos (Figura 5) producto del cono de aproximación al ex-aeropuerto (llustre Municipalidad de Cerrillos, 2011), susceptibles de ser urbanizados y constituir otro polo para la ciudad de Santiago, favorecido por la reciente apertura de la línea 6 del metro (2017) con la parada de Cerrillos, las conexiones a grandes vías de comunicación y la ciclovía. En el sector se emplazan también el Museo Aeronáutico, el Centro Cultural Lalo Parra, la Biblioteca Pública de Cerrillos y próximamente se abrirá una sede del Museo de Historia Natural. Además de estos hitos urbanos, destaca la proximidad y conexión con el parque Portal Bicentenario de 50 ha, que se traza, según indican sus autores:

[A] partir de la pista de aterrizaje existente como elemento organizador con un sistema de parques transversales y vías parque que complementan la función del parque central y ligan los distintos distritos del proyecto constituyendo una imagen de 'ciudad parque'. ... El parque central es una pieza clave y su diseño responde tanto a la voluntad de construir una imagen reconocible con relación al eje definido por la pista aeronáutica y su posible proyección hasta el anillo de circunvalación Américo Vespucio, como a la necesidad de su uso cotidiano como corazón del proyecto, lugar de encuentro y de paso para sus habitantes y los del entorno. (Lobos Beach y Montealegre, 2007, p. 2)

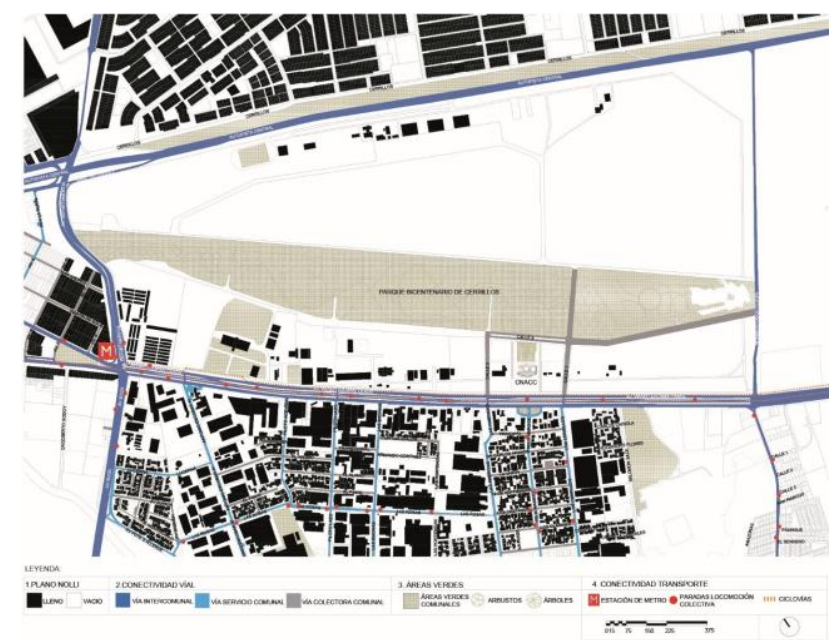

Figura 5. Plano de emplazamiento del CNACC en relación al barrio, con la superposición de información de: plano Nolli, Conectividad y áreas verdes. Fuente: Elaboración propia, basado en planos entregados por CNACC, corroborados en terreno y Google Earth.

Este parque recoge solo algunos aspectos del proyecto inicial de Ciudad del Viento, basado en la idea de una ciudad sustentable, que ganó el Concurso Internacional de Ideas organizado en 2001 por Ministerio de Vivienda y Urbanismo (MINVU) en conjunto con el Colegio de Arquitectos de Chile (Eliash, 2006) con la finalidad de seleccionar un diseño que propusiera al aeródromo como centro de un proyecto urbano (González Aguayo, 2010).

EI CNACC constituye un hito urbano, ya que articula el proyecto de gestión urbana Ciudad Parque Bicentenario (CPB), dirigido por el Ministerio de Vivienda y Urbanismo. Este último aspira albergar, en 20 años, a unas 16.500 familias. Los lineamientos estratégicos del CPB se definieron en base al Plan Maestro de Ciudad Parque Bicentenario, desarrollado entre los años 2003-2005 por el consorcio Asociación Portal Bicentenario liderado por URBE arquitectos, a partir de tres criterios urbanos (González Aguayo, 2010): 
Zonificación base. Articula el proyecto en torno al parque central Bicentenario con distintas franjas de usos y densidades.

Generación de conectividad. A través de vías que estructuran el conjunto y permiten conectar con las comunas colindantes.

Valorización de lo existente. Construcción de un centro cívico localizado en la zona donde se ubica el actual CNACC, en conexión con el Museo Aeronáutico y el Centro Cultural Lalo Parra. En acuerdo con Lynch, la torre de control y las características arquitectónicas de la edificación, la constituirían en un hito urbano "fácilmente identificable" (2006, p. 11).

\section{La edificación del CNACC}

La actual edificación del CNACC ha sido sometida a distintas transformaciones (Figura 6).

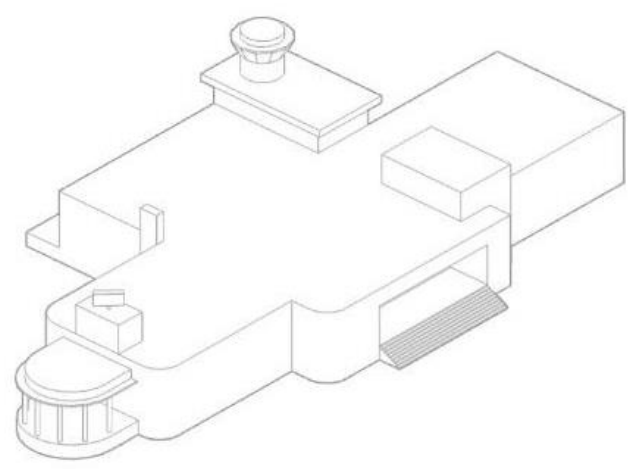

\section{AXONOMETRICA VOLUMEN EDIFICIO ORIGINAL} FECHA: 1933

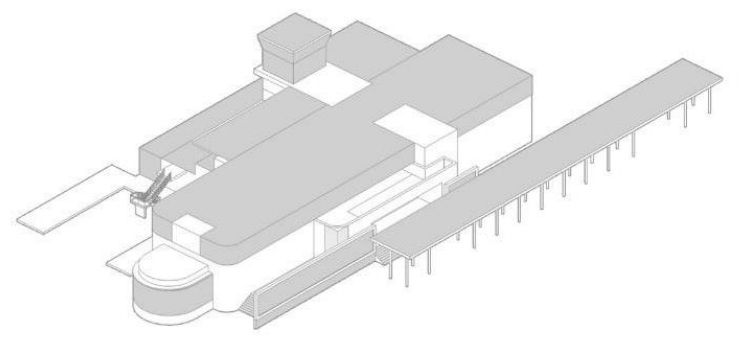

AXONOMETRICA VOLUMEN ACTUAL FECHA: ABRIL 2013

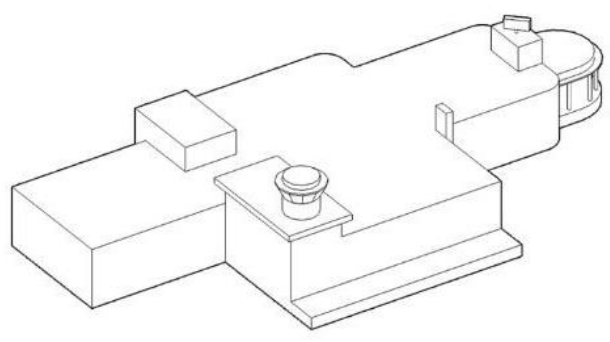

AXONOMETRICA VOLUMEN EDIFICIO ORIGINAL ธะกบห. 1 กว

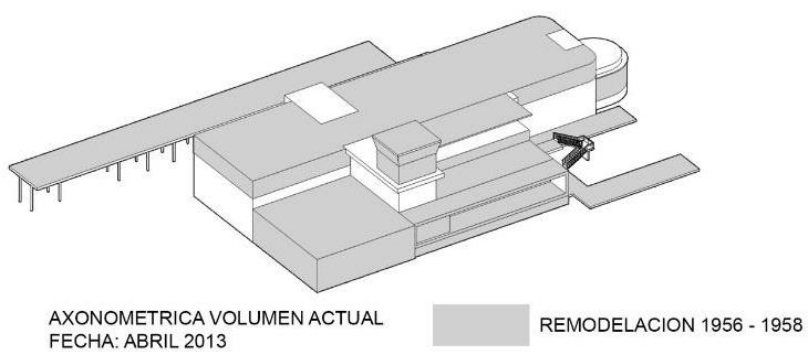

Figura 6. Axonométricas del aeropuerto de Cerrillos y remodelaciones hasta el actual CNACC. Fuente: Eliash, 2013.

El acceso al CNACC se realiza por dos sectores. Uno de ellos es por Av. Pedro Aguirre Cerda. Como se aprecia en la imagen (Figura 8) allí existe una valla que divide el terreno del centro con la vereda, la cual -según señala la directora de ese momento, Beatriz Salinas, en entrevista (29 junio 2018)- están intentado eliminar. Desde este acceso, la antigua torre de control es poco reconocible a nivel de calle debido a la incorporación de la tercera planta en la última remodelación del ex - aeropuerto. Lo mismo ocurre con las letras situadas en el acceso principal que, desde la vereda, son poco visibles. La valla y la escasa visibilidad dificultan el acercamiento de la comunidad a la edificación, a pesar de contar con una gran explanada de antesala. El otro acceso es por el parque Portal Bicentenario de Cerrillos. Desde allí sí es visible la ex-torre de control que, junto con las franjas de pavimento que conectan con el parque, invitan a acercarse al Centro de Arte como se observa en la Figura 7. Ambas entradas (Figura 7 y Figura 8) cuentan con acceso universal. 


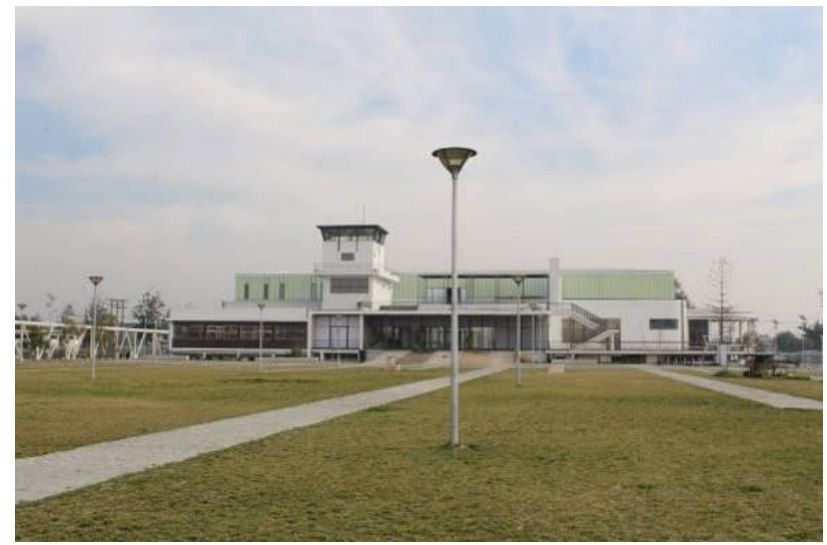

Figura 7. Imagen del acceso por la vereda de Av. Pedro Aguirre Cerda. Fuente: Elaboración propia.

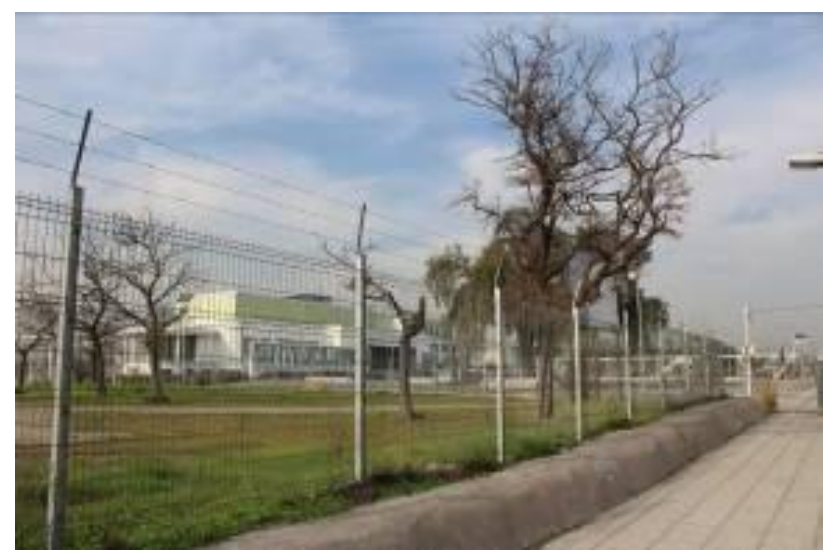

Figura 8. Imagen del acceso por el parque Portal Bicentenario Fuente: Elaboración propia. Fuente: Elaboración propia.

Al interior del Centro, en la planta +1 nivel de calle, se sitúa un hall central que conecta ambos accesos y que, en ocasiones, se utiliza como soporte de obras de exhibición. En este mismo nivel se encuentran distintas salas de exposiciones, el Centro de Documentación de Artes Visuales (CEDOC), la sala de exposición experimental y los baños de mujeres, como se muestra en el plano (Figura 9).

En el nivel -1, se sitúa una sala de exposiciones alrededor del núcleo del ascensor. Este piso cuenta con un acceso independiente para la llegada de las obras, además de bodegas, depósitos de obras, taller pañol y salas de cuarentena para el proceso de exposición. También se sitúan los talleres de mediación, baños de hombres, baño universal, sala multiuso y una sala de exposición permanente, además de los baños y cocina del personal (Figura 10). En el nivel +2 se encuentra la sala de exposición principal, con una pequeña bodega. En el sector este y oeste están las oficinas, junto con unas amplias terrazas hacia la cordillera de los Andes, como se muestra en el plano (Figura 11). En el nivel +3 , en la antigua torre de control se encuentra una sala de usos múltiples con vista hacia la cordillera, como se observa en el plano (Figura 12).

A pesar de que la edificación original fue un aeropuerto, los espacios servidores y servidos en el CNACC, se diferencian con claridad. Sin embargo, existen demasiados núcleos de escaleras con relación a la superficie de la planta, como se muestra en el siguiente análisis planimétrico (Figuras 9 a 12). 

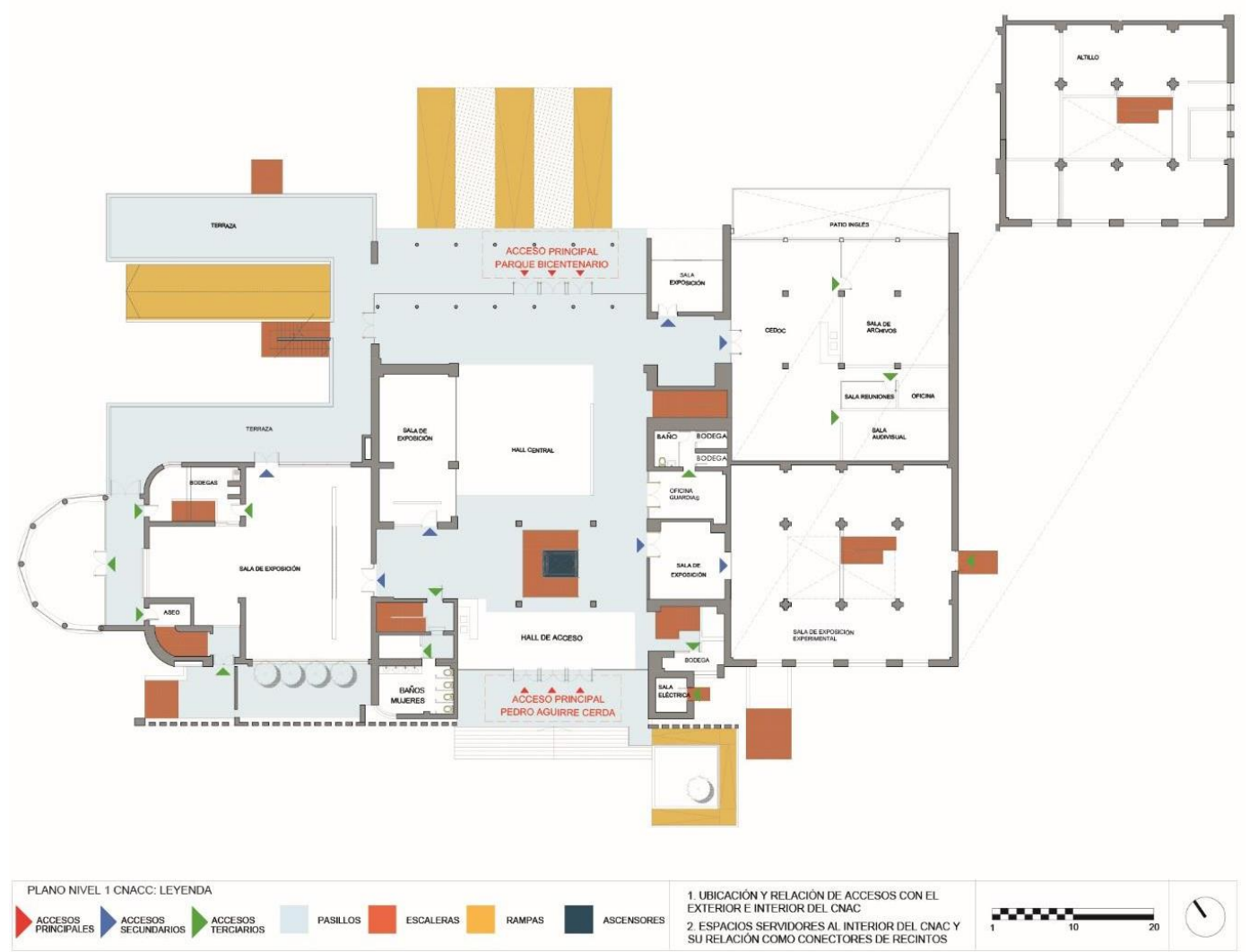

Figura 9. Plano nivel 1 CNACC. Fuente: Elaboración propia, basado en planos entregados por CNACC, corroborados en terreno.

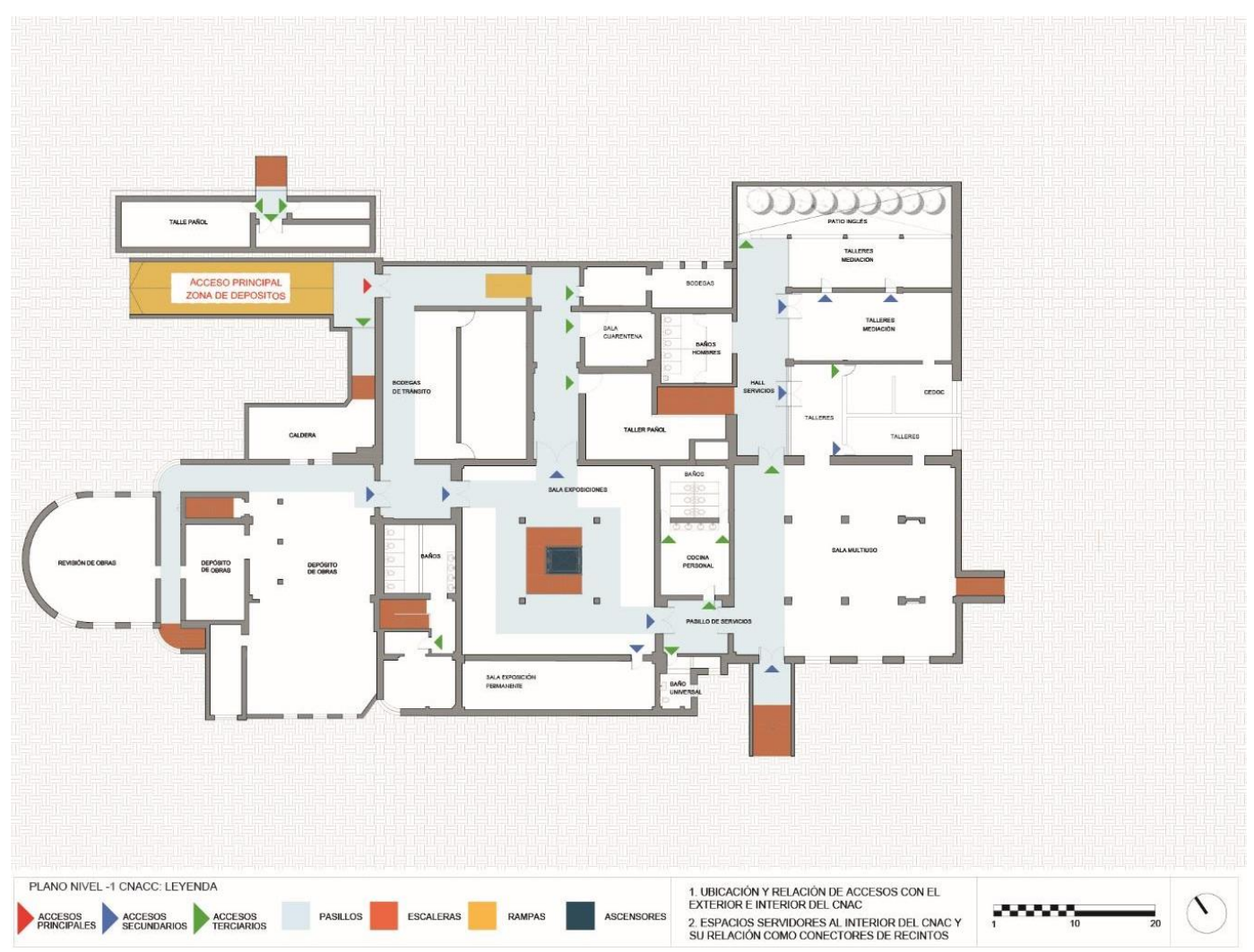

Figura 10. Plano nivel -1 CNACC. Fuente: Elaboración propia, basado en planos entregados por CNACC, corroborados en terreno. 


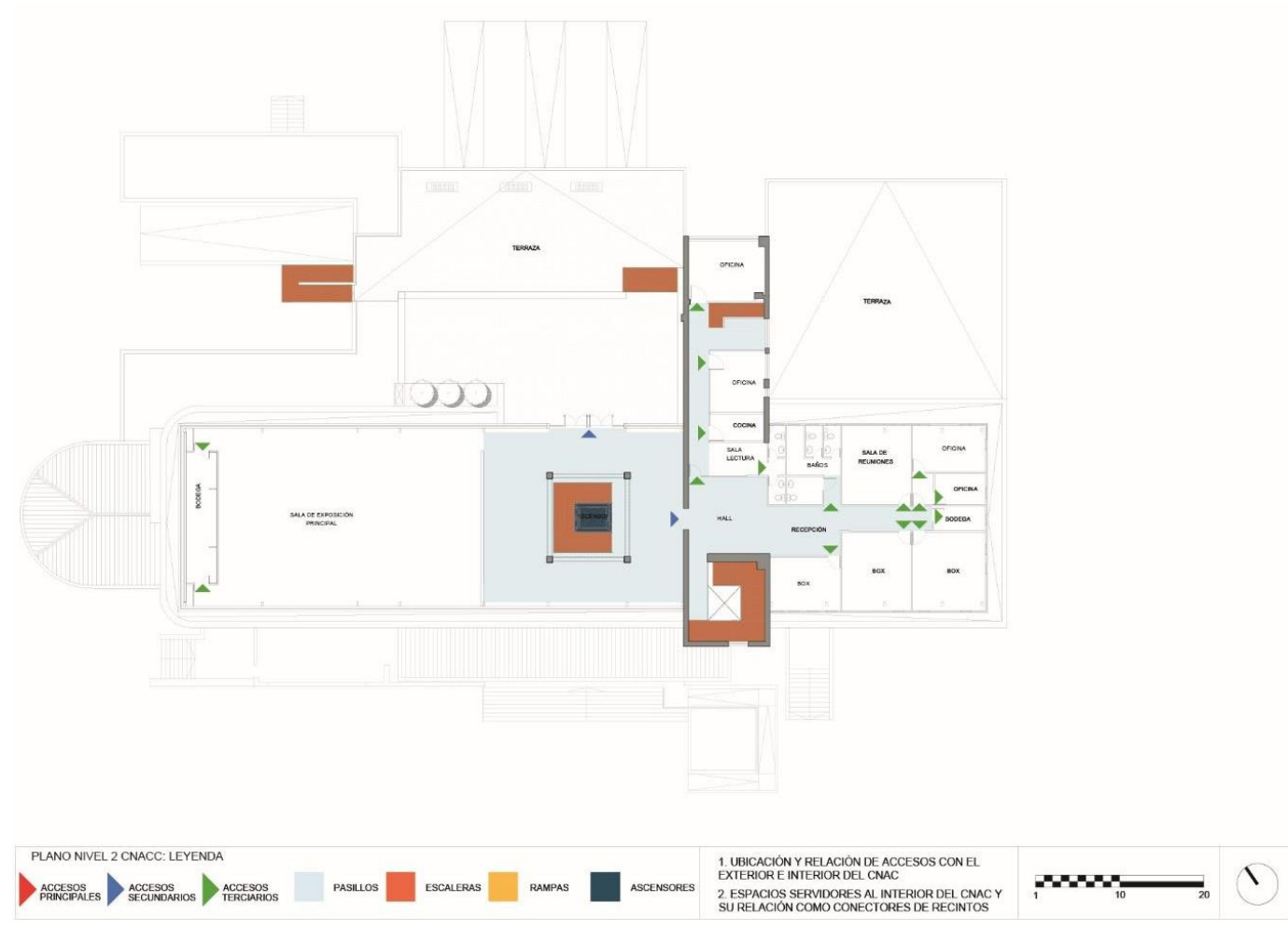

Figura 11. Plano nivel +2 CNACC. Fuente: Elaboración propia, basado en planos entregados por CNACC, corroborados en terreno.
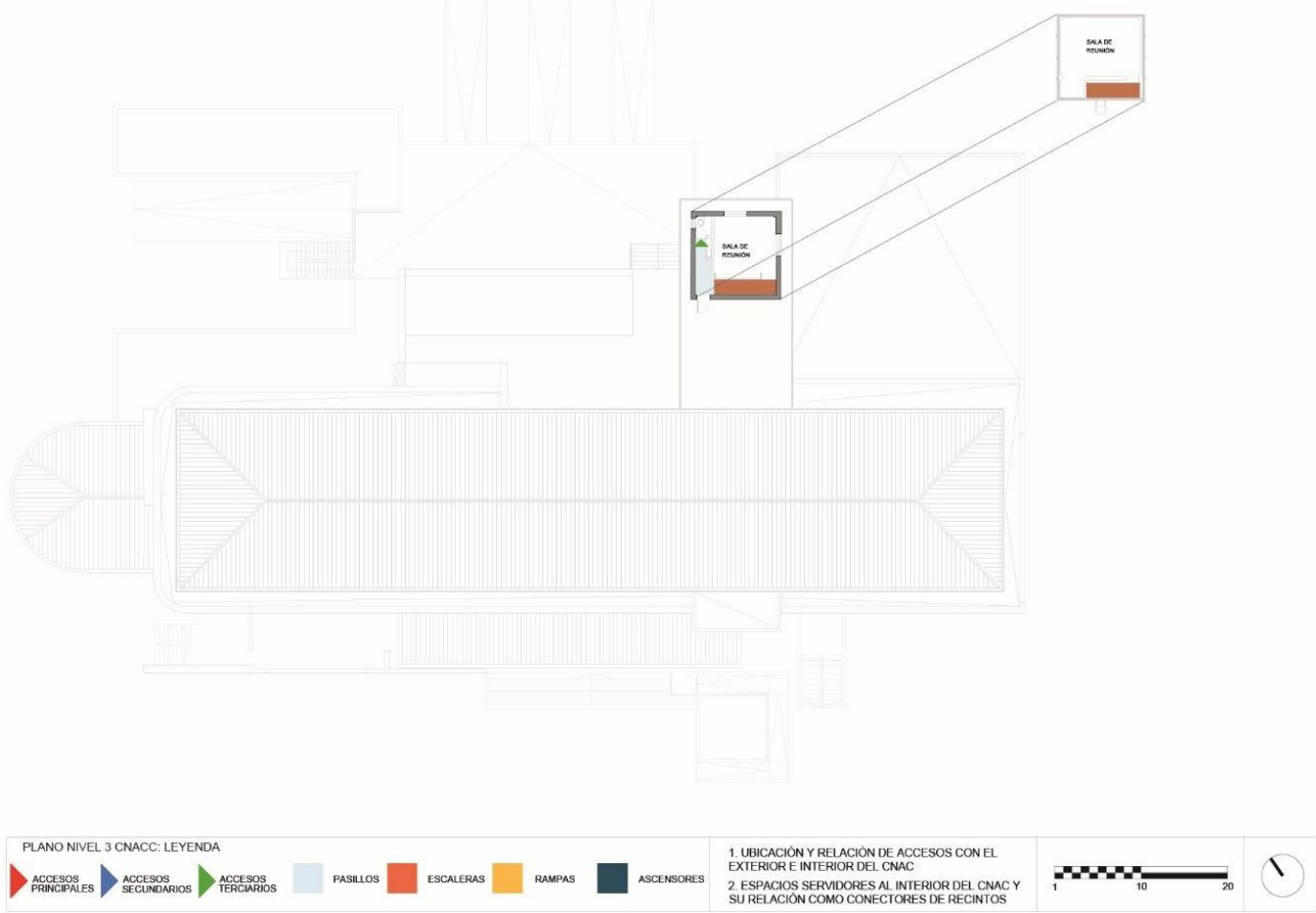

Figura 12. Plano nivel +3 CNACC. Fuente: Elaboración propia, basado en planos entregados por CNACC, corroborados en terreno. 
Las alturas entre losas, que oscilan entre los 2,9 $\mathrm{m}$ en la planta -1, $4 \mathrm{~m}$ en el hall principal y 3,7 $\mathrm{m}$ en la sala de exposición principal del nivel +2 (Figura 13), hacen posible la exhibición de distintas exposiciones. Además, la entrada de luz natural desde el exterior permite una buena iluminación en las salas principales.
La edificación mantiene las fachadas originales (Figura 7y Figura 8), su volumen circular, el mural y la antigua torre de control, que dialogan con la ampliación del segundo piso, produciendo un encuentro de volumetrías, colores y materiales.
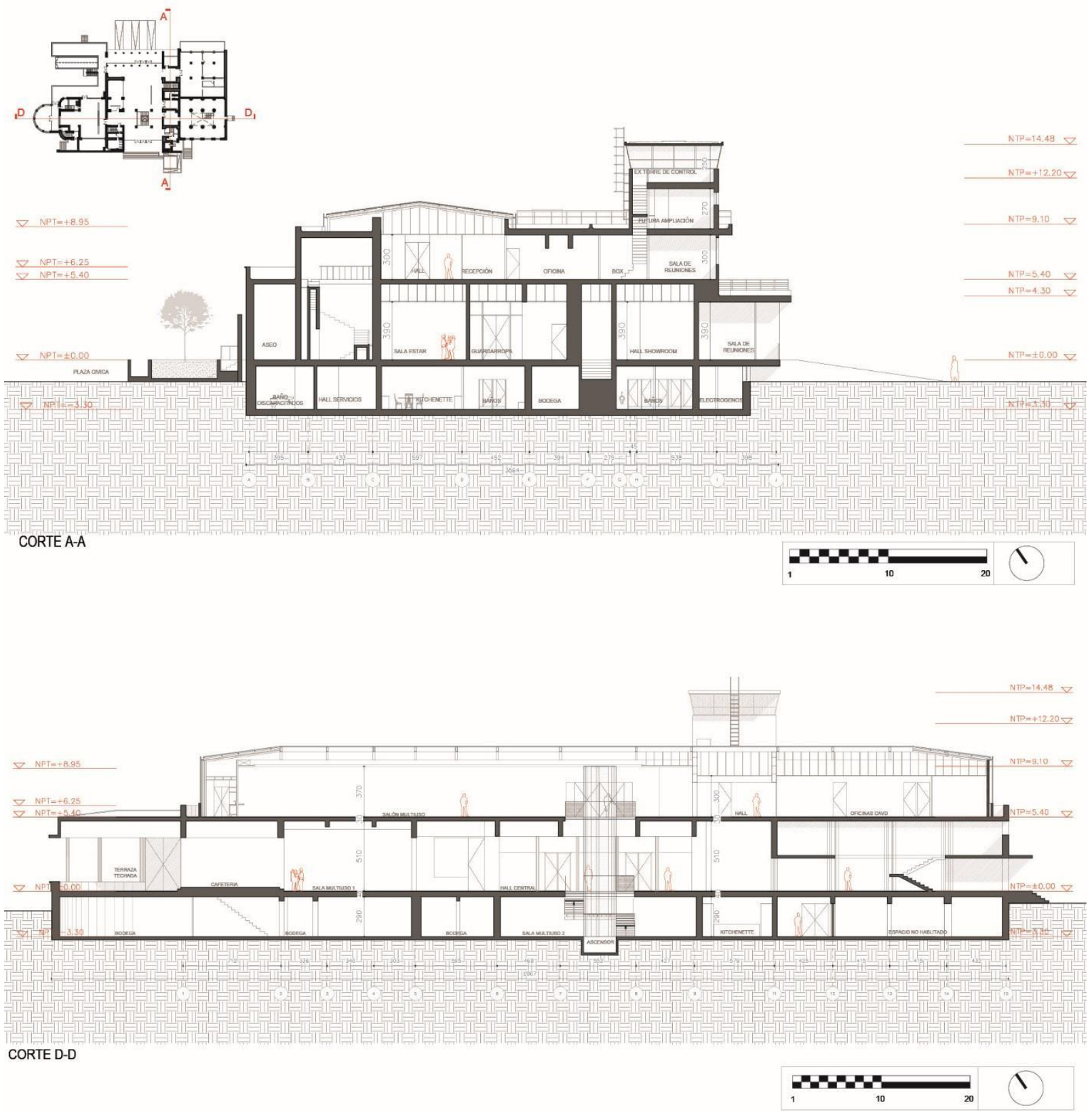

Figura 13. Cortes del CNACC. Fuente: Elaboración propia, basado en planos entregados por CNACC, corroborados en terreno. 


\section{La experiencia de los visitantes}

El personal que trabaja en el Centro Nacional de Arte Contemporáneo Cerrillos se ocupa de las áreas de exposición, investigación y mediación. La mayoría de ellos -directora, mediadores y funcionarios- se ubica en las oficinas del piso +2 . En la planta +1 trabaja el personal del Centro de Documentación de Artes Visuales (CEDOC) y la recepcionista que resuelve las inquietudes de los visitantes. Al interior del Centro circulan trabajadores de empresas externas que prestan servicios de vigilancia y aseo. En las plazas de acceso trabajan funcionarios de la Ilustre Municipalidad de Cerrillos que se ocupan de la mantención de las áreas verdes.

Hay personas que transitan por el sector e ingresan, pero, la mayoría de los visitantes proviene de otras comunas, particularmente de la zona oriente de Santiago, aunque otros residen o trabajan en Cerrillos. Tienen distintas edades y niveles educacionales. Acuden solos, en parejas, en familia o en grupos de estudiantes con sus profesores. Entre los visitantes se cuentan quienes ingresan a ver las exposiciones y quienes participan en actividades de mediación que organiza el CNACC. Estas están dirigidas especialmente a niños y vecinos adultos mayores. Cuando se trata de niños, van acompañados de un adulto. También hay quienes acuden directamente al CEDOC a consultar los archivos de arte. Este último es un público especializado: profesionales, investigadores, artistas, curadores y estudiantes.

Los visitantes y los trabajadores consideran que el CNACC no es muy conocido debido a la falta de difusión. Los primeros cuentan que acuden a las exposiciones porque se han informado de boca en boca, pero luego de tener conocimiento de las actividades, algunos buscan más información en la página Web institucional. También hay visitantes que reportan haberse informado de las exposiciones por medio de la radio, la televisión y las redes sociales.

Mientras que los visitantes que viven en la comuna llegan caminando, quienes vienen desde comunas lejanas planifican su viaje. Estos últimos utilizan diferentes medios de transporte como el automóvil, los buses de locomoción colectiva, el metro o la bicicleta. La conectividad es bien valorada y la existencia de la nueva estación de metro, facilita el acceso.
Aunque en el imaginario de los visitantes de comunas lejanas, el centro se encuentra en un lugar apartado de la ciudad y de difícil acceso, luego de su visita, este se modifica. Un residente de la Comuna de Ñuñoa comenta “... pensé que era difícil llegar, pero no era complicado" (Entrevista $\mathrm{N}^{\circ} 13$ ). Otra visitante que habita en el centro de la ciudad lo confirma, señalando: “Pensé que era más complicado" (Entrevista $\mathrm{N}^{\circ} 12$ ). Sin embargo, en la estación de metro más cercana no hay señalización alguna que informe sobre la ruta hacia el CNACC. Nada indica tampoco que es posible tomar un bus para recorrer el kilómetro y medio que lo separa de la estación.

EI CNACC se ubica, según los visitantes, en un sector de la ciudad lejos del lugar de residencia de los grupos económica y culturalmente privilegiados. Por ello, un visitante de la zona oriente de Santiago dice: "El problema es que queda muy alejado" (Entrevista $\mathrm{N}^{\circ} 25$ ). Sin embargo, otro residente del mismo sector explica: "Para nosotros era lejos... Pero, en Santiago todo es lejos. Así que, da lo mismo donde uno tenga que ir" (Entrevista $\mathrm{N}^{\circ} 7$ ). Además, "... queda cerca de donde viven otras personas" (Entrevista $\mathrm{N}^{\circ} 1$ ), argumenta otro residente también de una comuna lejana.

Los habitantes del sector oriente de la capital valoran que el nuevo centro haya sido inaugurado en el sector poniente, donde antes no se tenía acceso al arte, así, los habitantes de Cerrillos y las comunas cercanas pueden visitarlo. Además, consideran que la inauguración del CNACC ha revitalizado la zona. Por ello, un residente del sector central de la ciudad comenta: “... es bueno porque permite activar otras zonas. Es bueno que no todos los museos estén en Plaza Italia... hacia el sector oriente de la capital" (Entrevista $\mathrm{N}^{\circ} 12$ ). Otro visitante que habita una comuna del oriente argumenta: “... es bueno descentralizar un poco y que esté acá" (Entrevista N¹3). Además, para los habitantes de la comuna, explica un vecino, el edificio actual “... mantiene la identidad, porque... sigue siendo el edificio del Aeropuerto Cerrillos. Por algo tiene el nombre de la comuna" (Entrevista $N^{\circ} 2$ ).

Dado que el centro se emplaza en una zona industrial, por las calles aledañas no abundan los transeúntes que, sin mediar planificación, puedan decir: “... voy a entrar al museo” (Entrevista N¹4). Además, al estar emplazado sobre un gran espacio vacío, un visitante que habita una 
comuna lejana, explica “... vimos lo bonito que estaba la Cordillera de los Andes" (Entrevistado $\mathrm{N}^{\circ} 6$ ).

Cuando los adultos mayores visitan el CNACC surgen los recuerdos. Una visitante cuenta: "Yo vine al aeropuerto... Entonces, uno tiene una remembranza.... Veías a la gente que estaba encima del avión... Yo vine. No me subí al avión aquí. ... Pero vine a buscar y a dejar personas al aeropuerto" (Entrevista $\mathrm{N}^{\circ} 25$ ). $\mathrm{Y}$ un guardia del centro explica: "Yo también conocí el aeropuerto, pero nunca había entrado. ... A mí me encanta, porque soy de la época en que esto era aeropuerto... Veías despegar y aterrizar aviones" (Entrevista N²3).

Para los visitantes que no conocían el aeropuerto, “... arquitectónicamente, es un edificio bastante tosco para ser un museo de arte. ... Este parece más un edificio convencional... Parece más un estacionamiento" (Entrevista $\mathrm{N}^{\circ} 15$ ). Los visitantes de otras comunas piensan que debería haber señalética que informen la existencia del centro. Esto porque desde fuera el CNACC “... no invita a entrar. Faltan más anuncios o algo que te indique que es un museo" (Entrevista $\left.\mathrm{N}^{\circ} 15\right)$. Por eso, una acompañante de un niño que asiste a una actividad de mediación propone: “... hay que darle un poquito más de escenografía al museo. De vivir la experiencia del arte desde el minuto en que uno entra. A los alrededores, uno tiene que percibir que el arte se está desarrollando dentro del museo" (Entrevista N¹9). Además, explican los visitantes, la reja que se ubica a lo largo del frontis no permite visualizar el acceso, ni menos saber si está abierto o cerrado.

La fachada, según una visitante que habita en una comuna cercana, "... parece como la típica empresa... Yo, le hubiese puesto un poco más entretenido o más innovador... Como algo que te invite a entrar, que te diga: 'aquí tenemos cosas para aprender, para conocer'... Si tú lo miras así, parece hasta un hospital" (Entrevista $N^{\circ} 5$ ). Además, una visitante de la muestra Algoritmos agrega: "Si paso por afuera, jamás me daría cuenta que es un centro de arte. Es como feo, los colores. Es poco atractivo" (Entrevista $\mathrm{N}^{\circ} 9$ ). También indican que las letras que informan el nombre del CNACC son muy pequeñas y no se visualizan con claridad por falta de contraste con el color de la fachada.
En el exterior, por los costados del edificio, se ubican los estacionamientos techados cuya accesibilidad es bien valorada por los visitantes. Sin embargo, señalan que es difícil identificar su entrada. También hay bicicleteros, pero son poco utilizados.

Los bancos situados en la explanada del ingreso por la Av. Pedro Aguirre Cerda fueron utilizados, luego de la apertura del CNACC, por jóvenes que practicaban skate y BMX. A algunos guardias les agradaba su presencia, pero otros los obligaban a abandonar el lugar. Luego, debido al daño que provocaron, la administración autorizó la utilización de solo dos bancos.

En la plaza posterior del centro, durante los fines de semana de la exposición Algoritmos del Viento, se instalaron Food Trucks y pequeños quitasoles para que los visitantes pudieran permanecer sobre el pasto. Ahí también se pusieron en movimiento algunas de las obras de Theo Jansen. Durante esos días, los numerosos visitantes también usaron los bancos ubicados bajo los corredores techados para protegerse del sol, descansar y consumir refrigerios.

Los visitantes ingresan al edificio por uno de sus dos accesos: por la puerta principal, suelen entrar quienes llegan por medio del transporte público $y$, por la parte posterior, quienes se trasladan en automóvil o caminan desde el Parque Bicentenario.

Los visitantes consideran que las salas son adecuadas y que el espacio interior es amplio (Figura 14), por ello, la acompañante de un niño que participa en una actividad de mediación, dice que las salas,

... tienen una buena dimensión para poder desarrollar las obras en términos conceptuales, ya que el arte conceptual requiere de instalaciones, requiere de espacios. ... La misma exposición de la obra de Werken, de las 1000 máscaras, requiere de un espacio para instalarlas. (Entrevista №19)

Cuando el acceso al público no está controlado, los visitantes circulan libremente al interior del centro. No hay señalética que indique la ubicación de las salas y las obras exhibidas que no están a simple vista. 

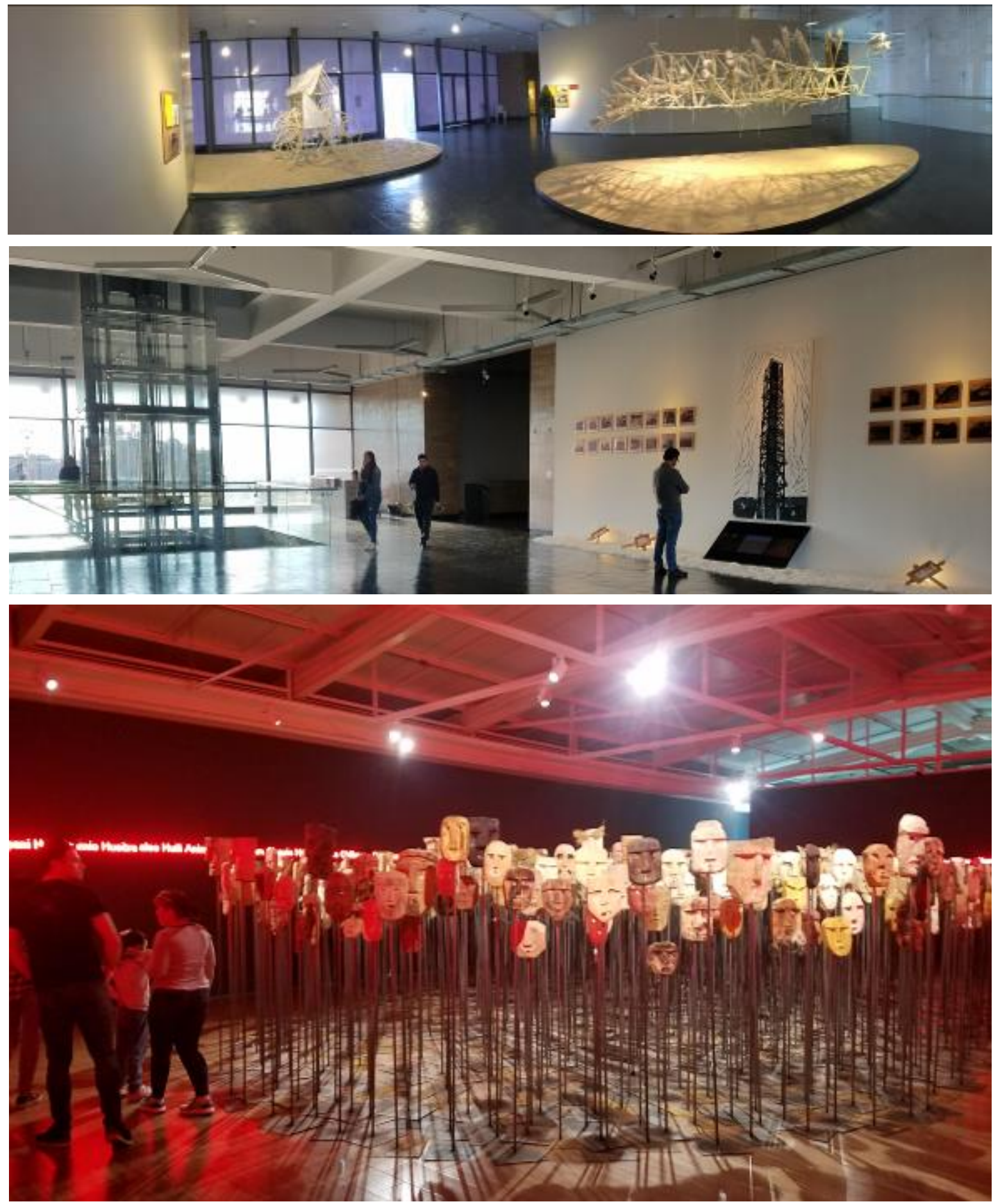

Figura 14. Salas principales de exposición. Arriba: Imagen Sala central de la primera planta durante exposición Algoritmos del Viento de Theo Jansen, el domingo 10 de julio del 2018, a las 14:05 horas. Centro: Imagen Sala central de la primera planta durante la exposición Diásporas, el miércoles 15 de agosto del 2018, a las 17:36 horas. Abajo: Imagen Sala principal de la segunda planta durante la exposición Diásporas, el miércoles 15 de agosto del 2018 , a las 17:34 horas. Fuente: Elaboración propia. 
Los baños para hombres y mujeres se encuentran en pisos diferentes. Lo mismo ocurre con los baños destinados a personas con movilidad reducida. Además, explica la acompañante de un niño que asiste a una actividad de mediación, la visita,

... puede ser un poco compleja para personas con movilidad limitada, por la cantidad de escaleras que tiene... Habría que habilitar el edificio para personas con movilidad reducida. Más ascensores, más rampas... Que los baños estén separados por una escalera, - el baño de hombres del baño de mujeres -, es una cosa que hay que trabajar. (Entrevista №19)

Tampoco hay adecuación para personas con discapacidad visual. Sin embargo, una visitante con movilidad reducida indica que al exterior existen rampas y al interior un ascensor que facilitan el desplazamiento.

Durante el fin de semana asisten alrededor de cien personas a las exposiciones. Sin embargo, durante la exhibición de Algoritmos del Viento, de Theo Jansen, la convocatoria fue masiva $y$ en algunos momentos fue necesario regular el ingreso y la permanencia de las personas en las salas.

Al interior del centro se realizan acciones de mediación. Se trata de actividades educativas y de experimentación en torno al arte contemporáneo: se realizan talleres, laboratorios, jornadas y campamentos de educación artística. Siempre se relacionan con la muestra en exposición y finalizan con un recorrido guiado. Son los mediadores quienes conciben y realizan estas actividades. También despliegan creativas estrategias para convocar a los vecinos. Pero, no siempre logran la convocatoria esperada. Por eso, un mediador explica: "Hay cosas que se hacen que todavía no son tan visibles" (Entrevista №22).

Sorprende a los visitantes que habitan la comuna que una exposición del prestigio de Algoritmos del Viento de Theo Jansen haya sido montada en un sector de la ciudad que no es económica ni culturalmente privilegiado. Esto permite el acceso al arte a los habitantes del sector. También se valoran positivamente los montajes y la experiencia de visita, más cuando la exposición se prolonga al patio trasero. Sin embargo, indican que falta mobiliario para el descanso y una cafetería. Un guardia explica que hay personas que llegan preguntando dónde se puede tomar un café. Además, aún no se ha establecido el vínculo entre el centro y parque. Un visitante señala: "Podría haber más información dentro del parque, porque hay gente que llega al parque y cree que esto todavía es el edificio antiguo y no sabe que hay un museo acá" (Entrevista $\mathrm{N}^{\circ} 2$ ).

\section{Discusión y conclusiones}

A partir del análisis inductivo de la información se identificaron 5 elementos que permiten establecer la capacidad de transformación que tiene el CNACC: conectividad, legibilidad, accesibilidad, recorridos y permanencias, y flexibilidad.

La existencia de una red de conectividad y la buena calidad del transporte acrecientan en los visitantes la percepción de cercanía del CNACC ubicado lejos del centro de la ciudad y de los centros de arte existentes en Santiago. Esta percepción es compartida por quienes se desplazan en bicicleta, transporte público (buses y metro) y vehículos particulares. Cabe destacar que, la apertura de la estación de metro Cerrillos fue clave para conectar el centro con el resto de la ciudad. El metro es un facilitador que da sentido de conectividad, modernidad y comodidad. Es la existencia de una diversidad de tipos de transportes lo que promueve y agiliza las visitas de personas de distintos sectores, en una ciudad altamente segmentada en términos sociales, culturales y económicos, y lo vincula al sistema urbano. Sin embargo, la conectividad se ve afectada por la inexistencia de señalética que una la salida de la estación del metro con el CNACC, a lo que se suma la ausencia de indicaciones para el ingreso de los vehículos al estacionamiento.

La torre de control, el volumen circular de su arquitectura y el mural de los Cóndores, aseguran la legibilidad y permiten vincular el centro con el hito urbano constituido por el antiguo aeropuerto. Estas imágenes activan la memoria y potencian la identidad comunal. Se suma a esto que, la programación del centro está concebida para visibilizar la edificación original. A saber, algunas de las principales actividades se nominan con terminología vinculada a la aeronáutica: Programa Hélice o Programa Planeadores. Además, algunos de los espacios emblemáticos -como la torre de control y las explanadas de acceso- se utilizan para desarrollar actividades de mediación; y en una de las plazas se exponen objetos de 
arte vinculados a la aviación. Sin embargo, el color blanco, la forma, el tamaño y escaso contraste de las letras que indican el nombre del centro, y la ausencia de más señalética impiden la correcta legibilidad del CNACC. Otro elemento que afecta a su legibilidad es la existencia de un imaginario de los visitantes respecto de la edificación de los centros de arte como una obra de arte única y monumental que marca la diferencia con las construcciones aledañas e indica su presencia. Se espera que la edificación comunique por sí misma que se trata de un lugar de arte y para el arte.

El hecho que el edificio del CNACC cuente con dos accesos principales favorece la entrada de los visitantes. Esto diversifica las rutas de ingreso: los visitantes que usan transporte público llegan por la avenida Pedro Aguirre Cerda y los visitantes, usuarios de transporte particular, por el Parque Bicentenario. Las franjas de pavimento que conectan el parque con el centro direccionan a los visitantes. La presencia de rampas facilita el ingreso de personas con movilidad reducida y la existencia de un ascensor ubicado al interior del centro favorece la conexión de todas las plantas, a pesar de no ser visibilizado por los visitantes que no requieren de estos dispositivos. Por su parte, el acceso al centro por la avenida Pedro Aguirre Cerda presenta obstáculos: la valla que lo separa de la acera se lee como una prohibición de ingreso y limita la libre circulación de los posibles visitantes; el retranqueo de la fachada genera una sombra que dificulta la visibilidad de la entrada, lo que impide saber si el centro está abierto o cerrado; y, por último, la existencia de una escalera de acceso al edificio se presenta como una barrera física.

El recorrido de los visitantes al interior del centro se ve favorecido por el contraste entre las proporciones de los accesos principales con los de las distintas salas y oficinas, lo que permite diferenciar tres niveles de acceso que guían el recorrido a los diferentes recintos. Pero, la ausencia de señalética que indique la existencia de salas diferentes y de lo expuesto en ellas, dificulta el libre recorrido. Lo mismo sucede con la percepción de los visitantes respecto de la escasa diferenciación entre los espacios servidores y servidos. Por último, la inexistencia de lugares de permanencia al interior del centro, durante y al final del recorrido, restringe la prolongación de las visitas.

La flexibilidad se ve favorecida por: la existencia de plazas aledañas que prolongan el espacio expositivo y vinculan el interior del centro con el exterior; la distancia, tanto a nivel horizontal como vertical, entre los elementos estructurales que posibilita la exposición de distintas obras, aunque no las de gran tamaño; y la existencia de iluminación natural en la mayoría de las salas que permite la graduación de la luz de acuerdo con los requerimientos curatoriales.

En definitiva, existe una base de conectividad estructural, pero falta un trabajo de habilitación de terminaciones que acondicionen la llegada del visitante. En lo que respecta a la legibilidad, esta está restringida a quienes conocieron la construcción antigua y a quienes son activos visitantes de lugares de arte, pero no es legible para las personas que circulan por las inmediaciones. Aunque el edificio cumple con todas las condiciones para el acceso, la valla que cierra el centro limita la accesibilidad. La estructura del edificio facilita el recorrido y tiene la posibilidad de incorporar sectores y puntos de permanencia. Sin embargo, la falta de señalética que favorezca la fluidez de recorridos y la inexistencia de mobiliario que permita la permanencia, disminuye la calidad de la experiencia del visitante. Por último, el centro cuenta con condiciones para acoger diversos tipos de muestras de arte dada la condición de flexibilidad de la edificación.

Por tanto, podemos afirmar que el Centro Nacional de Arte Contemporáneo de Cerrillos tiene el potencial necesario para constituirse en un motor de transformación de la ciudad, puesto que cuenta con las condiciones estructurales o de base [R] 


\section{Referencias}

Centro Nacional de Arte Contemporáneo Cerrillos (2016) Catálogo: Una imagen llamada palabra. Disponible en http://centronacionaldearte.cl/wpcontent/uploads/2016/09/catalogo-imagen-Ilamadapalabra.pdf

Comisión Nacional sobre Prisión Política y Tortura (2005) Informe de la Comisión Nacional sobre Prisión Política y Tortura. Santiago: La Nación S.A.

Consejo Nacional de la Cultura y las Artes (s.f.). Política de fomento de las artes visuales (2010-2015). Disponible en https://www.cultura.gob.cl/wpcontent/uploads/2011/11/politica_artesvisuales.pdf

Corominas, J. (1987). Breve diccionario etimológico de la lengua castellana. Madrid: Gredos.

Correa, S. et.al. (2001) Historia del siglo XX chileno. Santiago: Editorial Sudamericana.

De Ramón, A. (2000). Santiago de Chile (1541-1991). Historia de una sociedad urbana. Santiago: Editorial Sudamericana.

Echegoyen Olleta, J. (1996). Historia de la Filosofía: Filosofía Griega. Edinumen

Eliash, H. (2006). Portal Bicentenario: breve crónica de un proyecto urbano emblemático. Revista de Arquitectura, 12(13), Pág. 56-58. https://doi.org/10.5354/0719-5427.2013.28297

Eliash, H. (2013) Análisis histórico edificio ex terminal aéreo de Cerrillos. Santiago: s/e.

Esteban, I. (2007). El efecto Guggenheim del espacio basura al ornamento. Barcelona: Anagrama.

Galilea, S. (2006). Proyecto Portal Bicentenario. Revista de Arquitectura, 13.

Galland, D. (2014). Procesos y estilos de planificación en la rehabilitación urbana: el caso de Dinamarca. Revista de Arquitectura, 19(27), Pág. 15-24. https://doi.org/10.5354/0719-5427.2014.33564

González Aguayo, R. (2010). El proyecto "Ciudad del Viento", Portal Bicentenario, Cerrillos: fecundidad de una idea modelo de diseño urbano sustentable. Revista de Urbanismo, (22), 12-57. doi:10.5354/0717-5051.2010.8832
Ilustre Municipalidad de Cerrillos (2011). Plan de Desarrollo Comunal (PLADECO). Disponible en https://www.mcerrillos.cl/pdf/pladeco-cerrillos2011.pdf

Layuno Rosas, María Ángeles (2003). Museos de arte contemporáneo y ciudad. Los límites del objeto arquitectónico. En: Lorente, Jesús Pedro y Almazán, David (Ed.), Museología crítica y arte contemporáneo (pp. 109-123). Zaragoza: Prensas Universitarias.

Lobos Beach, M. y Montealegre Klenner, A. (2007). El Parque Portal Bicentenario en Santiago de Chile. Revista de Urbanismo, (16). https://doi.org/10.5354/0717-5051.2010.298

Lynch, K. (2006). La imagen de la ciudad. Barcelona: Gustavo Gili.

Mayring, Philipp (2014). Qualitative content analysis. Theoretical foundation, basic procedures and software solution. Disponible en https://www.psychopen.eu/fileadmin/user upload/b ooks/mayring/ssoar-2014-mayring-

Qualitative content analysis theoretical foundation. pdf

Miles, M., Huberman, M. \& J. Saldaña (2014). Qualitative data analysis: a methods sourcebook. Los Ángeles: SAGE.

Ministerio de las Culturas, las Artes y el Patrimonio inaugura Centro Nacional de Arte Contemporáneo Cerrillos con homenaje a José Balmes. (2016). Disponible en https://www.cultura.gob.cl/eventosactividades/centro-cerrillos-abre-sus-puertas-conexposicion-que-resume-medio-siglo-de-artecontemporaneo-chileno/

Montalbán, C. (1996) Ensayos de la Historia de Maipú. Material para la formulación del Currículum Escolar. Santiago: Codeduc/Corporación Municipal de Servicios y Desarrollo de Maipú y ECO - Educación y Comunicaciones.

Mujica, D. (s.f.) Cordones industriales. Cronología comentada. Santiago: Biblioteca de Historia Obrera. 
Pires, A. (1997). Échantillonnage et recherche qualitative : essai théorique et méthodologique. En J. Poupart, J.P. Deslauriers, L.H. Groulx, A. Lapirrière, R. Mayer \& A. Pires, La recherche qualitative. Enjeux épistémologiques et méthodologiques (pp. 113-167). Québec: Gaëtan Morin Éditeur.

Rinke, S. (2013) Encuentros con el Yanqui: Norteamericanización y cambio sociocultural en Chile 1898-1990. Santiago: Dibam.

Valdivia, V. (2015). La democracia dictatorial pinochetista: regionalización y municipios. Avances del Cesar, (12), 171-187.

Valenzuela, F.A., Espinosa, A., Madero-Cabib, I., Moyano, C., Ortiz, F. (2015). Los museos de arte como mecanismos de inclusión y exclusión social en el arte y en la sociedad: un estudio de caso en Chile. Boletim do Museo Paraense Emilio Goeldi, 10(3), 723-737.
Zunzunegui, S. (1990). Metamorfosis de la mirada: el museo como espacio del sentido. Sevilla: Alfar.

\section{Agradecimientos}

Beatriz Salinas, directora Del Centro Nacional de Arte Contemporáneo Cerrillos.

Valentina Mardini, Ministerio de Vivienda y Urbanismo.

Humberto Eliash, arquitecto de la última remodelación CNACC.

Eduardo Zenteno, Ministerio de Vivienda y Urbanismo. Soledad Novoa, historiadora. 